\title{
Lacrimal scintigraphy. II. Its role in the diagnosis of epiphora
}

\author{
L. A. AMANAT, ${ }^{1}$ T. E. HILDITCH, ${ }^{2}$ and C. S. KWOK ${ }^{2 *}$ \\ From the ${ }^{1}$ Tennent Institute of Ophthalmology, University of Glasgow, Western Infirmary, Glasgow, and the \\ Department of Clinical Physics and Bio-Engineering, West of Scotland Health Boards, Glasgow
}

SUMMARY Lacrimal scintigraphy (LS) was performed in 860 lacrimal drainage systems (LDS) in 188 patients with bilateral epiphora and 226 patients with unilateral epiphora. A very high incidence of canalicular obstruction was found in these patients, the incidence being higher in the group with unilateral epiphora. It is suggested that a canalicular block is a commoner cause of obstructive epiphora than has been recognised previously and that LS is a reliable method of studying the canalicular function. A significant number (42\%) of the opposite asymptomatic eyes of patients with unilateral epiphora were found to have an abnormality in the LDS, which supports the view that abnormalities in the LDS tend to be bilateral. Only $25 \%$ of these asymptomatic systems showed a normal drainage, confirming that physiological obstruction can exist below the lacrimal sac in normal lacrimal drainage systems.

Epiphora is a common clinical condition which confronts almost every ophthalmologist in clinical practice. According to Jones one-third of patients who see an ophthalmologist have epiphora or its related complications. ${ }^{1}$ This is a very high figure when compared with the experience of Foster,${ }^{2}$ who found that about $3-4 \%$ of patients attending an eye clinic in the United Kingdom complained of an excess of tears. In the vast majority of patients the epiphora is due to an obstruction in the lacrimal drainage system (LDS), and, since the treatment is invariably surgical, a careful assessment of the drainage is necessary to determine accurately the level of lacrimal obstruction. A careful examination and syringing may not always provide enough information of the anatomical abnormalities and the physiological function.

Numerous diagnostic tests are available to assist in the diagnosis, some of which are simple, others difficult to perform and interpret. Perhaps subtraction macrodacryocystography (SMDCG) is the most widely used, but although it is extremely valuable in demonstrating anatomical abnormalities of the $\mathrm{LDS}^{3}$ it provides limited information about the physiology of the system. Lacrimal scintigraphy (LS)—also

*Present address: Department of Physics, Hamilton Clinic, Hamilton, Ontario, Canada.

Correspondence to Mr L. A. Amanat, FRCS, District General Hospital, Lowestoft Road, Gorleston, Great Yarmouth. termed lacrimal scintillography, nuclear DCG, nuclear lacrimal scan, microscintigraphy, and dacryoscintigraphy-first described by Rossomondo et al. ${ }^{4}$ is a more physiological test and provides useful information about the dynamics of lacrimal drainage. Although it was found to be superior to dacryocystography (DCG) in some studies ${ }^{56}$ Hurwitz et al. pointed out that, unless used with quantitation, scintigraphy alone was of limited value and that even then quantitative lacrimal scintillography (QLS) was merely complementary to intubation macrodacryocystography, and the 2 investigations interpreted together gave the maximum possible clinical information. ${ }^{7}$ Amanat et al. ${ }^{8}$ however, recommended that SMDCG should be performed only if LS had failed to diagnose the obstruction, since in their experience the exact site of obstruction could be accurately diagnosed in most patients by LS alone. In a study of asymptomatic volunteers it was found that QLS provided a sensitive and reproducible test of canalicular function but had no role in the clinical evaluation of lacrimal drainage from the lacrimal sac to the nose. ${ }^{9}$

In view of this controversy surrounding the clinical value of LS the present study was undertaken to determine whether LS used alone was sufficient to provide enough information about the further management of a patient with epiphora and to establish whether quantitative criteria were necessary in 
clinical practice. It was hoped that the study would also provide information on the mechanism of drainage from the nasolacrimal duct to the nose in normals and in patients with symptoms, and on the question whether the distribution of the nature and site of obstruction as diagnosed by LS was comparable to that diagnosed by dacryostography and reported in other studies.

\section{Material and methods}

We included all patients in this study who were referred to the Lacrimal Scintigraphy Clinic for investigation of their epiphora. All patients had a careful examination to detect any obvious abnormalities of the eyelids and lacrimal puncta. Any abnormality found was taken into consideration during the analysis of the study, as were the findings of syringing when available.

Bilateral LS was performed in 415 patients, out of whom 156 were males and 259 females. The age of patients ranged from 3 to 96 years. Twelve patients had the LS repeated once, while 2 patients had LS performed 3 times. Thus altogether 862 systems were studied in these patients.

\section{TECHNIQUE OF LS}

Before the test begins, the procedure is explained to the patient in brief. With a felt-tipped pen a mark is made at the midline on the forehead just above the bridge of the patient's nose, who then sits upright with the chin and forehead stabilised on an adjustable stand secured to the $2.5 \mathrm{~mm}$ pinhole collimator of an Ohio Nuclear Series 100 gamma camera which is interfaced to a Varian V76 computer. The necessary adjustments are made to ensure that the distance between the patient's cornea and the pinhole is approximately $85 \mathrm{~mm}$, and then a band is tied round the head to minimise any involuntary movements by the patient. We now believe that it is unncessary to empty the lacrimal sac by digital expression. With the patient seated comfortably the study is commenced and 12 seconds later $2 \mathrm{MBq}$ of technetium $\left({ }^{99 \mathrm{~m}} \mathrm{Tc}\right)$ tin colloid in $15 \mu \mathrm{l}$ isotonic saline are instilled simultaneously into the eyes at the lateral canthi using micropipettes. The patient is instructed to continue blinking normally. The flow of the tracer through the lacrimal passages is displayed on an oscilloscope and on colour television display, with dynamic data being acquired in the form of 100 frames each of 6 seconds' duration which are stored on the magnetic disc of the computer. Static views are also reproduced simultaneously on black/white Polaroids at $0-30$ seconds, 31-60 seconds, 1-2 minutes, 2-4 minutes, 4-6 minutes, and 6-10 minutes. At 8 minutes a ${ }^{57} \mathrm{Co}$ marker source is placed
Table 1 Nature and site of obstruction in patients with bilateral epiphora

\begin{tabular}{lrr}
\hline Complete canalicular obstruction & 118 & $(31 \%)$ \\
Partial canalicular obstruction & 98 & $(26 \%)$ \\
Complete obstruction at lower end of lacrimal sac & 42 & $(11 \%)$ \\
Partial obstruction at lower end of lacrimal sac & 30 & $(8 \%)$ \\
Complete obstruction of nasolacrimal duct & 21 & $(5 \%)$ \\
Partial obstruction of nasolacrimal duct & 20 & $(5 \%)$ \\
Functional obstruction* & 12 & $(3 \%)$ \\
Patent dacryocystorhinostomy (DCR) & 1 & \\
Partially blocked DCR anastomosis & 1 & $(1 \%)$ \\
Technically unsatisfactory scan & 4 & $(2 \%)$ \\
Normal drainage with no demonstrable & \multicolumn{3}{|c}{} \\
$\quad$ obstruction & 33 & $(9 \%)$ \\
Total & 380 systems \\
\hline
\end{tabular}

*In functional obstruction there are symptoms of epiphora but no abnormality in the LDS either on DCG or on syringing.

on the mid-line mark and held there for a few seconds so that an identifiable landmark is registered on the data for reference when analysing the result. The study is terminated at 10 minutes, but, if a physiological obstruction is suspected at the level of the nasolacrimal duct (see later), the study is extended for a further 5 minutes, during which additional normal saline drops are added to the tear film and a static view for 10-15 minutes obtained on a Polaroid at the end of the study. The 100 dynamic frames are then integrated into a single frame to give a composite picture of the whole study, which is then displayed on the television screen. Four regions of interest are defined on each side outlining the conjunctival sac, the lacrimal sac, the nasolacrimal duct, and the nasal cavity and the computer generates the dynamic curves of changes in activity with time in these regions. The curves representing the 4 regions of each eye are displayed together on the television screen, photographed for records, and then studied in conjunction with the static views to diagnose the presence of any abnormality and the level at which it exists.

With the size of the pinhole collimator used by us it was not possible to visualise the upper and the lower canaliculi individually, since at a distance of 80-90 $\mathrm{mm}$ which we found was necessary to visualise the

Table 2 Nature and site of obstruction in patients with unilateral epiphora

\begin{tabular}{lrr}
\hline Complete canalicular obstruction & 123 & $(51 \%)$ \\
Partial canalicular obstruction & 50 & $(21 \%)$ \\
Complete obstruction at lower end of lacrimal sac & 24 & $(10 \%)$ \\
Partial obstruction at lower end of lacrimal sac & 9 & $(4 \%)$ \\
Complete obstruction of nasolacrimal duct & 7 & $(3 \%)$ \\
Partial obstruction of nasolacrimal duct & 10 & $(4 \%)$ \\
Functional obstruction & 5 & $(2 \%)$ \\
Patent dacryocystorhinostomy (DCR) & 1 & $(0 \cdot 5 \%)$ \\
Technically unsatisfactory scan & 1 & $(0 \cdot 5 \%)$ \\
Normal drainage with no demonstrable & \multicolumn{3}{c}{} \\
$\quad$ obstruction & 10 & $(4 \%)$ \\
Total & 240 systems \\
\hline
\end{tabular}




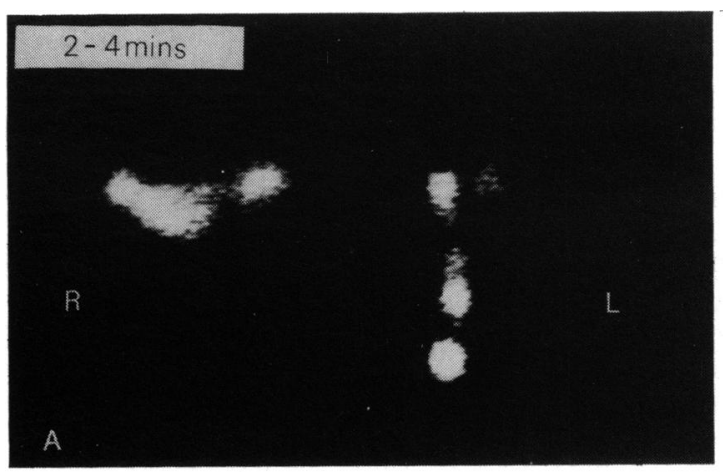

41

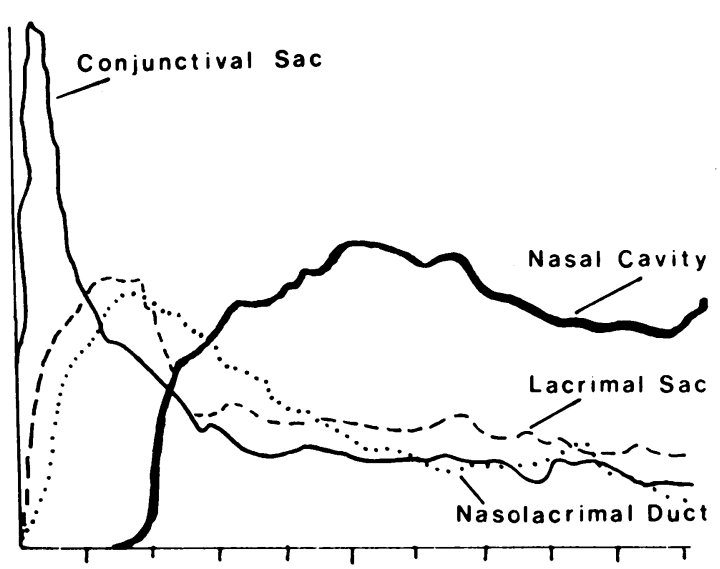

Left eye

Fig. 1 (A) Complete obstruction at canalicular level in patient with right-sided epiphora. Left side shows normal drainage. (B) Normal dynamic curves of left side.

Table 3 Analysis of obstruction in the symptomatic systems in all patients with epiphora

\begin{tabular}{lrr}
\hline Complete canalicular obstruction & 241 & $(39 \%)$ \\
Partial canalicular obstruction & 148 & $(24 \%)$ \\
Complete obstruction at lower end of lacrimal sac & 66 & $(11 \%)$ \\
Partial obstruction at lower end of lacrimal sac & 39 & $(6 \%)$ \\
Complete obstruction of nasolacrimal duct & 28 & $(4 \cdot 5 \%)$ \\
Partial obstruction of nasolacrimal duct & 30 & $(4 \cdot 8 \%)$ \\
Functional obstruction & 17 & $(2 \cdot 7 \%)$ \\
Patent dacryocystorhinostomy (DCR) & 2 & $(0 \cdot 3 \%)$ \\
Partially blocked DCR anastomosis & 1 & $(0 \cdot 15 \%)$ \\
Technically unsatisfactory scan & 5 & $(0 \cdot 8 \%)$ \\
Normal drainage with no demonstrable & \multicolumn{3}{c}{} \\
$\quad$ obstruction & 43 & $(7 \%)$ \\
Total & 620 systems \\
\hline
\end{tabular}

drainage of the 2 eyes simultaneously the system resolution was insufficient to separate these 2 structures. However, in those cases where information about the anatomy of the canaliculi is thought to be essential the patient is moved closer to the pinhole and the eye in question studied separately.

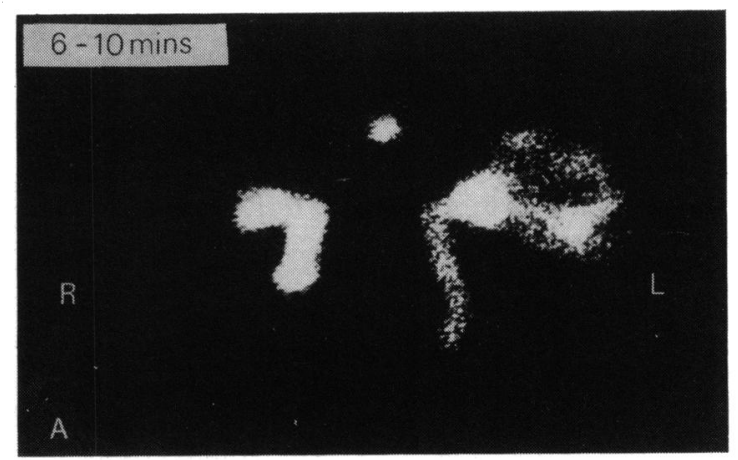

67

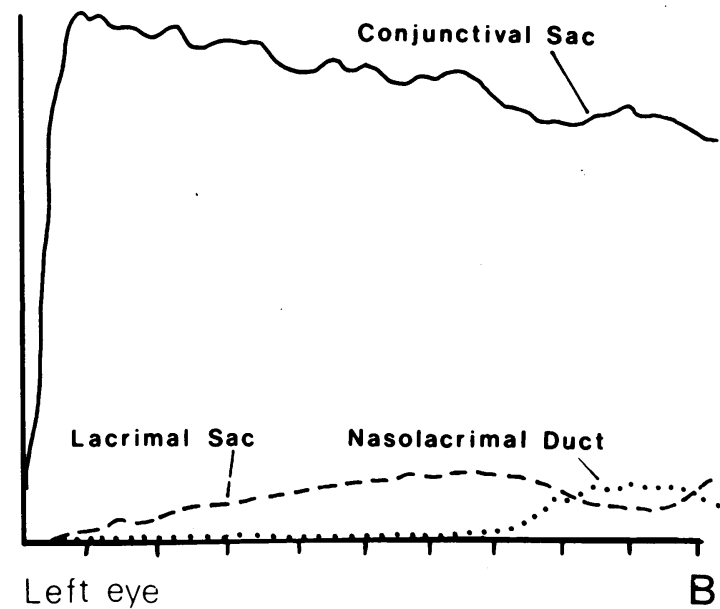

Fig. 2 (A) Right complete obstruction in the nasolacrimal duct and left partial common canalicular obstruction. (B) Dynamic curves for left side showing high levels of tracer in the conjunctival sac and low levels in the lacrimal sac and nasolacrimal duct.

\section{Results}

LS was performed on 415 patients, which to the best of our knowledge forms the largest series reported in the literature. In our study there were 188 patients with bilateral epiphora $(45.3 \%)$ and 226 patients (54.5\%) with unilateral epiphora; another patient had no symptoms but was referred for LS to confirm the patency of the dacryocystorhinostomy (DCR) that had been performed to relieve his symptoms of epiphora. Two of the patients with bilateral epiphora had LS repeated once, so that a total number of $\mathbf{3 8 0}$ systems wer studied in these patients. In the group with unilateral epiphora 10 patients had LS repeated once and 2 patients had LS performed thrice. The results of the investigations in these 2 groups of patients are given in Tables 1 and 2, while the nature and site of obstruction as diagnosed by LS in all the 414 patients is detailed in Table 3. Examples of the 


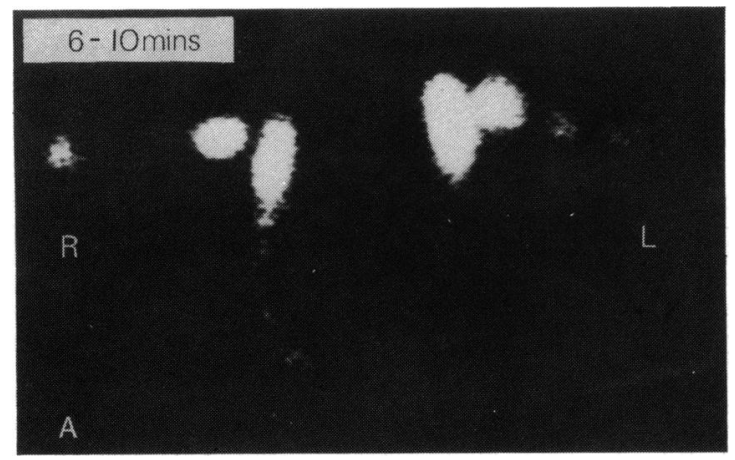

51

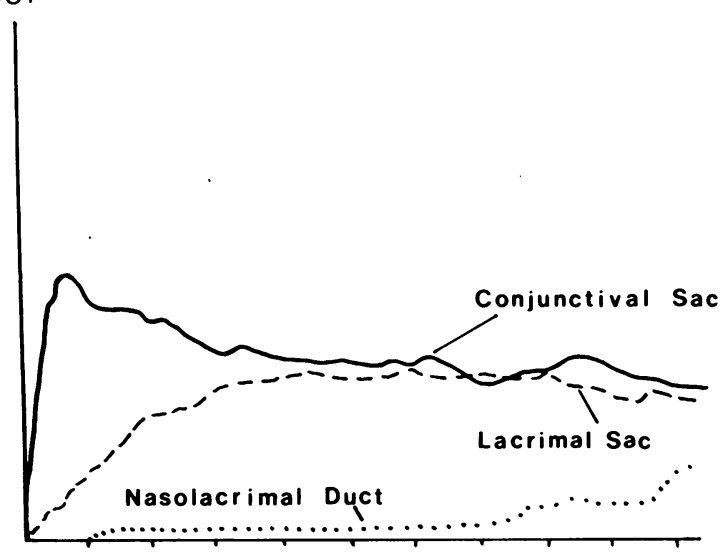

Right eye

Fig. 3 (A) Partial and complete obstruction below right and left lacrimal sac respectively. (B) Dynamic curves for right side showing high levels of tracer in lacrimal sac.

various types of obstruction are shown in Figs. 1-5.

The results obtained from the opposite asymptomatic eyes of the 226 patients with unilateral epiphora are shown in Table 4. Normal flow could be demonstrated in only $25 \%$ of the systems studied. $28 \%$ of the systems manifested physiological obstruction, i.e., either where tracer was present in the nasal cavity but the dynamic curves showed a delayed flow in the LDS (Fig. 6) or where patency of the nasolacrimal duct could be demonstrated only on overloading the tear film with saline drops (Fig. 7). A very high percentage $(42 \%)$ of asymptomatic systems had an obstruction in the LDS (Table 4), which was of a complete nature in $25 \%$ and of a partial nature in $17 \%$.

Fifty-two patients were referred for LS following various surgical procedures on the LDS (Table 5). Out of these, 17 had a DCR alone, 4 had intubation of canaliculi in addition, and 8 had a Lester Jones tube inserted at the time of surgery ( 32 systems). However, despite surgery symptoms of epiphora had persisted

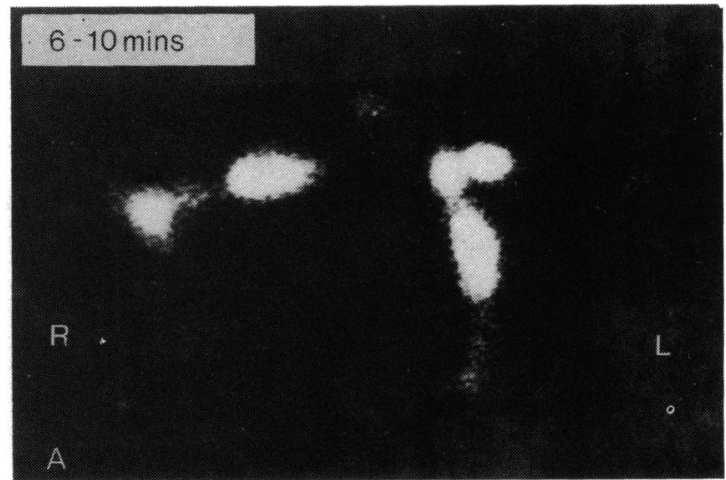

61

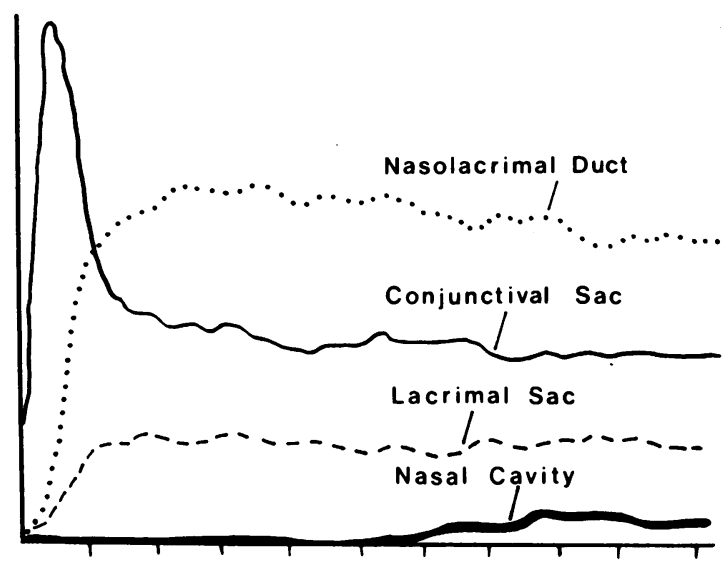

Left eye

Fig. 4(A) Complete right canalicular obstruction and partial obstruction at distal end of left nasolacrimal duct in patient with bilateral epiphora. (B) Dynamic studies showing high levels of tracer in left nasolacrimal duct.

in 23 of these 32 systems. There was no demonstrable flow of tracer into the lacrimal sac in 20 , indicating failed by-pass surgery; one system revealed a partial block of the DCR anastomosis, while the DCR was patent in the remaining 2. Patency of the DCR anastomosis was confirmed in 8 of the 9 asymptomic systems. The majority of the patients who received retropunctal cautery were found to have obstructed canaliculi. Four of the 5 patients who had intubation of canaliculi for trauma had patent canalicular system. The remaining 11 patients were all shown to have an obstruction in the LDS at some level.

In addition there were 18 other patients who complained of unilateral epiphora after receiving such injuries as fracture of malar bones, nasoethmoidal fractures, fracture of orbital bones (10 patients), and lacerations of the lower eyelid and medial canthus from knife wounds, dog bites, etc. (8 patients). 


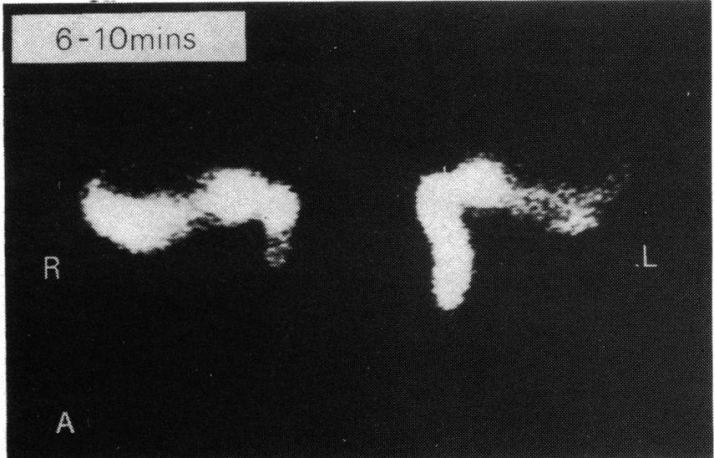

Fig. 5 Lacrimal scan of patient with bilateral epiphora showing a complete obstruction below right lacrimal sac and at distal end of left nasolacrimal duct.

36

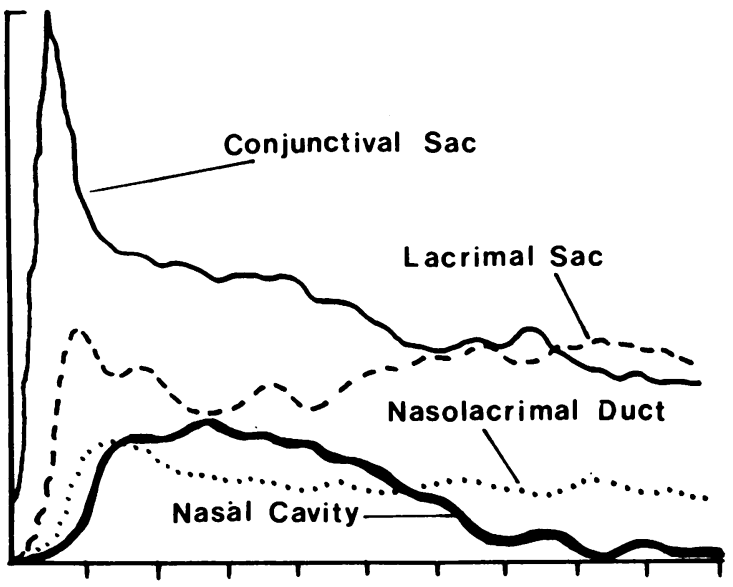

Left Eye

Fig. 6 Dynamic curves for left (asymptomatic) eye of a patient with right epiphora. Note the high levels of tracer in conjunctival and lacrimal sac in the presence of a patent LDS.

\section{Discussion}

There is little doubt that LS is an atraumatic procedure which is simple and easy to perform and is more physiological than either syringing or DCG. In

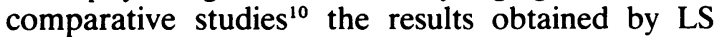
correlated well with those obtained by DCG, but Hurwitz et al. " did not agree with claims that LS would replace DCG. They considered that LS without quantitation gave limited information of the function of the LDS, and so from their studies on normals they proposed 6 measures of drainage in LS, namely, $T_{1 / 2}$ and $T_{\max }$ values for the lacrimal sac, the nasolacrimal duct, and the nose. In a later study ${ }^{12}$ they confirmed that in completely obstructed tear
Table 4 Results of lacrimal scintigraphy in asymptomatic systems

\begin{tabular}{lrr}
\hline Complete canalicular obstruction & 12 & $(5 \%)$ \\
Partial canalicular obstruction & 27 & $(11 \cdot 25 \%)$ \\
Complete obstruction at lower end of lacrimal sac & 27 & $(11 \cdot 25 \%)$ \\
Partial obstruction at lower end of lacrimal sac & 11 & $(4 \cdot 6 \%)$ \\
Complete obstruction of nasolacrimal duct & 21 & $(9 \%)$ \\
Partial obstruction of nasolacrimal duct & 3 & $(1 \cdot 25 \%)$ \\
Functional obstruction & 3 & $(1 \cdot 25 \%)$ \\
Patent dacryocystorhinostomy (DCR) & 7 & $(3 \%)$ \\
Blocked DCR anastomosis & 1 & $(0 \cdot 4 \%)$ \\
Normal drainage with no demonstrable & \multicolumn{2}{c}{} \\
$\quad$ obstruction & 61 & $(25 \%)$ \\
Normal drainage with physiological obstruction & 67 & $(28 \%)$ \\
Total & 240 systems \\
\end{tabular}

passages DCG provided virtually all the necessary information for the management of the case and that scintigraphy was helpful only when the obstruction was incomplete or a stenosis was present. In such cases and in patients with nonobstructive epiphora due to a functional obstruction ${ }^{13}$ they found that QLS combined with intubation SMDCG provided the most comprehensive anatomical and functional assessment of the LDS. Other workers, ${ }^{14}$ however, showed that the flow dynamics were dependent upon the volume of the fluid instilled and argued that investigations into the kinetics of tear flow using a certain volume do not necessarily mimic the flow dynamics under physiological conditions. Indeed a careful appraisal of the literature shows the great variation in the normal transit values to the sac, nasolacrimal duct, and the nose (Table 6). This wide range of transit times may also presumably be due to variations in the frequency and intensity of blinking, changes in the volume of tears produced, variations in tear flow, the resistance offered by the several valves in the LDS, and possibly other factors such as emotion and irritation of the conjunctiva.

We encountere ${ }^{15}$ similar difficulties in establishing normal values in asymptomatic individuals and showed that variable tear flow was a feature of normal lacrimal drainage, which made it difficult to analyse the data on the basis of linear flow as suggested by Hurwitz et al. Instead of using normal values for quantitation it was found that interpretation of the time activity curves together with the serial images and if necessary a repeat display of the 100 frames in sequence on the television screen provided the best method of analysing the information and diagnosing an abnormality in the lacrimal drainage. All conclusions were therefore based on this method of quantitation, and it was possible to provide an accurate diagnosis of the nature and the level of obstruction in all patients except 3 . In 2 the images acquired were blurred because of constant movements of the head, while the scan in the third patient was 


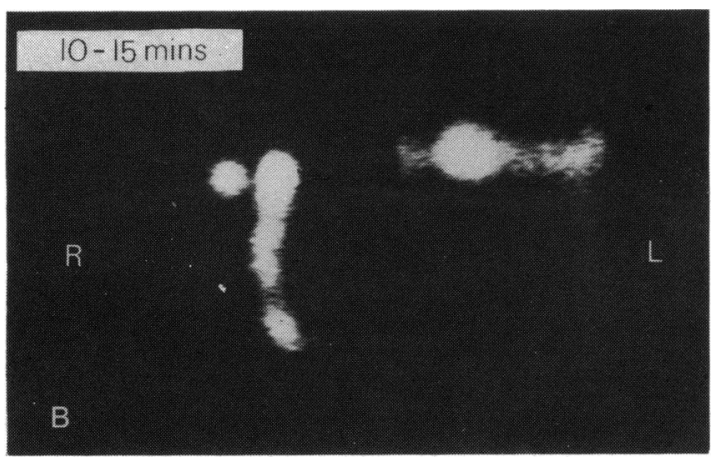

Fig. 7 In this patient with left epiphora there was no flow of tracer into the nose on the right asymptomatic side at the end of 10 minutes. Overloading the tear film, however, demonstrates the patency of the drainage system on the right side.

technically unsatisfactory because of the presence of ointment in the eye to be studied.

In approximately $28 \%$ of asymptomatic systems there was either no flow of tracer into the nose $(25$ systems), or, if tracer did flow into the nose, the dynamic curves indicated a hold-up in the sac or invariably in the nasolacrimal duct (42 systems). Patency of the nasolacrimal duct was confirmed in the 25 systems with no tracer in the nose by overloading the tear film with normal saline drops at the end of 10 minutes. This 'physiological' obstruction at the distal end of the nasolacrimal duct encountered on lacrimal scintigraphy has been demonstrated in numerous studies $^{91617}$ and may explain the variable and delayed transit of tracer into the nose. The possible explanations for such a phenomenon to exist in normal lacrimal drainage have been discussed elsewhere. ${ }^{18} \mathrm{It}$ is very important to differentiate a physiological obstruction from a true organic obstruction or a stenosis because of the clinical implications. From our experience we have learnt that the pattern of drainage is different in the 2 situations. In the presence of symptoms and high levels of tracer in the nasolacrimal duct the dynamic curves would support a diagnosis of a complete block if the addition of saline drops produces no flow of tracer into the nose. A stenosis or partial obstruction should be suspected if the overloading of the tear film results in some flow into the nose. On the other hand, if there are no symptoms, then in a physiological obstruction there is a rapid entry of technetium into the system, resulting in a uniform distribution of tracer throughout the several compartments (Fig. 8), reflected by a characteristic levelling-off of the corresponding dynamic curves, which then show little or no change until the physiological obstruction is overcome by repeated instillation of saline drops. The time-activity
Table 5 Details of surgical procedures performed on patients referred for lacrimal scintigraphy

\begin{tabular}{ll}
\hline Dacryocystorhinostomy (DCR) & 17 patients (18 systems) \\
DCR with intubation of canaliculi & 4 patients $(4$ systems) \\
DCR with insertion of Lester Jones tube & 8 patients $(10$ systems $)$ \\
Retropunctal cautery & 7 patients \\
Intubation of canaliculi following trauma & 5 patients \\
Probing & 3 patients \\
Surgery on puncta (3 snip etc.) & 3 patients \\
Dacryocystectomy & 2 patients \\
Punctal occlusion for keratoconjunctivitis & \\
$\quad$ sicca & 1 patient \\
Incision drainage of lacrimal sac abscess & 1 patient \\
Lid surgery for excision of rodent ulcer & 1 patient \\
Total & 52 patients \\
\hline
\end{tabular}

curves may not always demonstrate these characteristics, but, when the level of tracer in the nasolacrimal duct is higher than the levels of tracer in the other compartments, an organic obstruction should always be suspected.

A very high incidence of abnormality was found in the opposite asymptomatic eye of patients with unilateral epiphora. It is very difficult to explain the absence of symptoms in these eyes despite the recognised fact that abnormalities in the LDS, whether congenital or acquired, tend to be bilateral. ${ }^{19}$ It is quite likely that patients are not so conscious of or tend to ignore the symptoms on the opposite side if these are not so severe as on the presenting side. The majority of patients in whom an abnormality was detected on the opposite side had a canalicular obstruction on the symptomatic side. It may be that the symptoms of constant and persistent epiphora resulting from an obstruction in the common canaliculus are more distressing and annoying than symptoms of intermittent epiphora resulting from a partial obstruction or a distal obstruction, and the patient therefore complains of watering of the eye on one side only. Very often they would admit to some symptoms on the other side if questioned directly but

Table 6 Normal flow values for lacrimal scintigraphy

\begin{tabular}{|c|c|c|c|}
\hline & $\begin{array}{l}\text { Transit } \\
\text { time to } \\
\text { sac }\end{array}$ & $\begin{array}{l}\text { Transit } \\
\text { time to } \\
N L D\end{array}$ & $\begin{array}{l}\text { Transit time to } \\
\text { nose }\end{array}$ \\
\hline Brizel et al. ${ }^{17}$ & $0-120 \mathrm{~s}$ & $1-15 \mathrm{~min}$ & - \\
\hline Carlton et al. ${ }^{29}$ & $4-43 \mathrm{~s}$ & $4-323 \mathrm{~s}$ & - \\
\hline Hurwitz et al. ${ }^{\prime \prime}$ & $\begin{array}{l}1-15 \min \\
\left(T_{\max }\right)\end{array}$ & $\begin{array}{l}3-24 \min \\
\left(T_{\max }\right)\end{array}$ & $\begin{array}{l}0 \cdot 25-3 \cdot 0 \mathrm{~min} \\
\left(\mathrm{~T}_{\max }\right)\end{array}$ \\
\hline Chaudhuri et al. ${ }^{6}$ & - & - & $8-10 \mathrm{~min}$ \\
\hline Meyer and Dausch ${ }^{14}$ & - & - & $\begin{array}{r}11.6 \min \text { (using } 2 \mu \mathrm{l} \text { ) } \\
6.3 \mathrm{~min} \text { (using } 10 \mu \mathrm{l})\end{array}$ \\
\hline Chavis et al. ${ }^{9}$ & $6-18 s$ & $6 \mathrm{~s}-12 \mathrm{~min}$ & $30 \mathrm{~s}$ to any time \\
\hline Blanksma et al. ${ }^{16}$ & $30 \mathrm{~s}$ & - & - \\
\hline
\end{tabular}

$\mathrm{NLD}=$ nasolacrimal duct. 


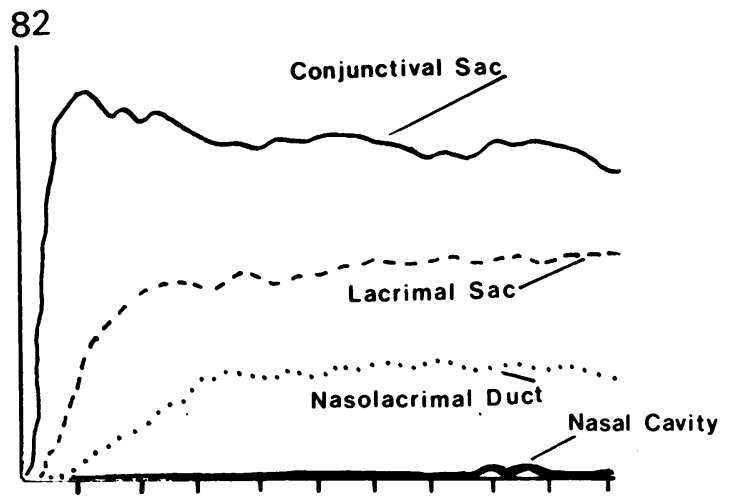

Left Eye

Fig. 8 Dynamic study of left (asymptomatic) eye with physiological obstruction showing an equilibrium of tracer in the several compartments.

would hasten to add that these are not so bad. We therefore recommend that all patients with epiphora should have bilateral studies, especially if a LS is being performed, since it will not only diagnose unsuspected abnormalities in the other eye but will give valuable information for comparison if the opposite side demonstrates a normal drainage. Hurwitz and Welham ${ }^{20}$ found that bilateral abnormality occurred in $55 \%$ of cases with congenital nasolacrimal duct obstruction. Similarly other workers ${ }^{21}$ found that $42 \%$ of adult patients with unilateral epiphora had an abnormal primary Jones test on the normal side. These figures compare favourably with our results (42\%).

It is believed that epiphora tends to be more common in females than males, and a ratio as high as 4:1 has been quoted in some reports. ${ }^{22}{ }^{23}$ This is, however, not borne out by our study, where, although there were more females than males, the ratio was just below 2:1 (259:156).

In those patients who had symptoms we found a complete obstruction in $54 \%$ of the symptomatic systems and a partial obstruction in $35 \%$; only $7 \%$ of the symptomatic systems were found to have no obstruction at all. Although this incidence correlates well with that reported in other studies (Table 7), the level at which the obstruction occurred was found to be different. In the present series we discovered that the most common site of obstruction diagnosed by LS was at the canalicular level (63\%). Saparoff $e$ et al. ${ }^{24}$ reported an incidence of $32 \%$ pre-sac anatomical block in 38 lacrimal scans, while Amanat et al. ${ }^{8}$ found a canalicular block in $38 \%$ of their series of 51 patients. These findings are significantly lower than ours, but because of the small number of patients studied in these 2 series a true comparison is not possible. However, other studies reporting the results obtained by dacryocystography also show a very low incidence of canalicular block (Table 8). Moreover, contrary to reports in the literature ${ }^{25}$ based upon DCG results, we did not find that a nasolacrimal duct obstruction was the commonest cause of unilateral epiphora; instead we found that a canalicular block was the more common site of obstruction in these patients $(72 \%$ as compared to $57 \%$ in bilateral epiphora).

Table 7 Nature of obstruction diagnosed by dacryocystography and lacrimal scintigraphy in varioüs studies

\begin{tabular}{|c|c|c|c|c|}
\hline & $\begin{array}{l}\text { No. of } \\
\text { patients }\end{array}$ & Complete obstruction & Partial obstruction & No obstruction \\
\hline \multicolumn{5}{|l|}{ Dacryocystography } \\
\hline Campbell ${ }^{30}$ & 200 & $56 \%$ & $44 \%$ & - \\
\hline Malik et al. ${ }^{23}$ & 169 & $80 \%$ & $8.8 \%$ & $11 \cdot 2 \%$ \\
\hline Amanat et al. ${ }^{8}$ & 79 (systems) & $44 \cdot 3 \%$ & $11 \cdot 4 \%$ & $44 \cdot 3 \%$ \\
\hline $\begin{array}{l}\text { Nahata }^{31} \\
\text { Lacrimal scintigraphy }\end{array}$ & 35 & $80 \%$ & $20 \%$ & \\
\hline Hurwitz et al. . $^{32}$ & 191 & $46 \%$ & $54 \%^{*}$ & \\
\hline Amanat et al. ${ }^{8}$ & 51 & $54 \%$ & $15 \%$ & $23 \%$ \\
\hline
\end{tabular}

${ }^{*}$ Includes incomplete obstructions and functional obstructions.

Table 8 Level of obstruction diagnosed by dacryocystography in various studies

\begin{tabular}{|c|c|c|c|c|}
\hline & $\begin{array}{l}\text { No. of } \\
\text { patients }\end{array}$ & Canalicular obstruction & $\begin{array}{l}\text { Obstruction below } \\
\text { lacrimal sac }\end{array}$ & $\begin{array}{l}\text { Obstruction of } \\
\text { nasolacrimal duct }\end{array}$ \\
\hline Campbell $^{30}$ & 200 & $22 \%$ & $62 \cdot 5 \%$ & $15 \cdot 5 \%$ \\
\hline Malik et al. ${ }^{23}$ & 169 & $24 \cdot 3 \%$ & $53 \cdot 2 \%$ & - \\
\hline Castren and Korhonen ${ }^{22}$ & 80 & $15 \%$ & $85 \%$ & - \\
\hline Nahata $^{31}$ & 35 & $5 \cdot 7 \%$ & $94 \cdot 3 \%$ & - \\
\hline Amanat et al. ${ }^{8}$ & 79 & $25 \%$ & $10 \%$ & $20 \%$ \\
\hline
\end{tabular}


Since these findings are in disagreement with published work, it is essential to rule out the possibility that the high figures for canalicular block in our investigations are due to inclusion of false positive results. This is important because the treatment of epiphora is invariably surgical, and the nature and the site of obstruction diagnosed by the preoperative investigation determines the choice of the operative procedure. Confirmation of the validity of the present findings can be obtained from reported studies ${ }^{9}$ on normal subjects which demonstrated an unobstructed flow between the conjunctival and lacrimal sacs in nearly every case. Furthermore only a small proportion of the asymptomatic systems in the present study group had a canalicular obstruction. We were thus satisfied that there was little likelihood of diagnosing false positives with this technique and that the results obtained were accurate.

In dacryocystography the dye is injected under pressure and this can sometimes give false resultsfor example, where an abnormal mucous membrane flap or a slight narrowing in the lumen of the lacrimal passages presents enough resistance to normal physiological flow to produce epiphora but not to the injection of dye. Dacryocystography is of little diagnostic value in canalicular disorders, ${ }^{26}$ especially canalicular stenosis. ${ }^{127}$ Furthermore in a series reviewed by Keast-Butler $e t$ al. ${ }^{27}$ it was found that a sac obstruction can be associated with a membrane at the medial end of the common canaliculus, which intubation macrodacrycystography would fail to diagnose unless combined with subtraction studies. In the series reviewed $40 \%$ of the patients had an obstruction at the medial end of the common canaliculus which was diagnosed inaccurately because bone-free studies were not used. In another study approximately one-third of simple dacryocystorhinostomies which failed to relieve epiphora were found to be due to nonrecognition of pre-existing common canalicular obstruction. ${ }^{28}$ It is quite likely that the frequency of canalicular block as the cause of obstructive epiphora has not been fully recognised and that the incidence is far higher than has been reported.

It is therefore very important that, in order to reduce the risk of surgical failure, the preoperative assessment should be as accurate as possible, and it is our view that LS combined with the method of quantitation described in this study provides the most reliable information for the proper management of a patient with epiphora. It is atraumatic and simple to perform, but, most important of all, its physiological nature renders it an invaluable diagnostic tool. The radiation delivered to the eye is relatively low ${ }^{33}$ and the colloidal tracer is not dissimilar to tear fluid, which makes it ideal for scintigraphy.
We thank the technical staff of the Nuclear Medicine Department, Western Infirmary, Glasgow, for their help and co-operation in this study, Mrs M. Borg and the staff of the Department of Medical Illustration, District General Hospital, Great Yarmouth, for preparing the illustrations, and Mrs R. Brown for her invaluable secretarial assistance and for typing the manuscript.

\section{References}

1 Jones LT. The lacrimal secretory system and its treatment. Arch Ophthalmol 1966; 62: 47-66.

2 Foster J. Evaluation of the current treatment of stricture of the valve of Krause. Ann R Coll Surg Engl 1956; 18: 143-63.

3 Hurwitz JJ, Welham RAN, Lloyd GAS. The role of intubation macro-dacryocystography in management of problems of the lacrimal system. Can J Ophthalmol 1975; 10: 361-6.

4 Rossomondo RM, Carlton WH, Trueblood JH, Thomas RP. A new method of evaluating lacrimal drainage. Arch Ophthalmol 1972: 88: 523-5.

5 Chaudhuri TK, Saparoff GR, Dolan KD, Chaudhuri TK. A comparative study of contrast dacryocystogram (DCG) and nuclear DCG. J Nucl Med Allied Sci 1974; 15: 482.

6 Chaudhuri TK, Saparoff GR, Dolan KD, Chaudhuri TK. A comparative study of contrast dacryocystogram and nuclear dacryocystogram. J Nucl Med Allied Sci 1975; 16: 605-8.

7 Hurwitz JJ, Maisey MN, Welham RAN. Quantitative lacrimal scintillography II. Lacrimal pathology. Br J Ophthalmol 1975; 59: 313-22.

8 Amanat LA, Wraight EP, Watson PG, Hawkins TD. Role of lacrimal scintigraphy and subtraction macrodacryocystography in the management of epiphora. Br J Ophthalmol 1979; 63: 511-9.

9 Chavis RM, Welham RAN, Maisey MN. Quantitative lacrimal scintillography. Arch Ophthalmol 1978; 96: 2066-8.

10 Chaudhuri TK. Nuclear dacryocystography. Appl Radiol 1975; 4: $127-8,150$.

11 Hurwitz JJ, Maisey MN, Welham RAN. Quantitative lacrimal scintillography. 1. Method and physiological application. Br J Ophthalmol 1975; 59: 308-12.

12 Hurwitz JJ, Welham RAN, Maisey MN. Intubation macrodacryocystography and quantitative scintillography: The 'complete' lacrimal assessment. Trans Am Acad Ophthalmol Otolaryngol 1976; 81: OP 575-82.

13 Demorest BH, Milder B. Dacryocystography II. The pathologic lacrimal apparatus. Arch Ophthalmol 1955; 54: 410-21.

14 Meyer PB, Dausch D. Klinische erfahrungen mit der radionuklid dacryozystographie. Klin Monatsbl Augenheilkd 1975; 167: 421-6.

15 Hilditch TE, Kwok CS, Amanat LA. Lacrimal scintigraphy I. Compartmental analysis of data. Br J Ophthalmol 1983; 67: 713-719.

16 Blanksma LJ, Schweitzer NMJ, Beekhuis H, Piers DA. Testing of lacrimal drainage with the aid of a gamma-ray emitting radio-

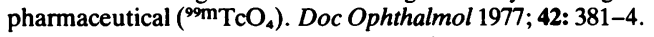

17 Brizel HE, Shells WC, Brown M. The effects of radiotherapy on the nasolacrimal system as evaluated by dacryoscintigraphy. Radiology 1975; 116: 373-81.

18 Amanat LA, Hilditch TE, Kwok CS. Lacrimal scintigraphy III. Physiological aspects of lacrimal drainage. Br J Ophthalmol 1983; 67: 719-732.

19 Lloyd GAS, Jones BR, Welham RAN. Intubation macrodacryocystography. Br J Ophthalmol 1972; 56: 600-3.

20 Hurwitz JJ, Welham RAN. The role of dacryocystography in the management of congenital nasolacrimal duct obstruction. Can J Ophthalmol 1975; 10: 346-50.

21 Zappia RJ, Milder B. Lacrimal drainage function 1. The Jones fluorescein test. Am J Ophthalmol 1972; 74: 154-9.

22 Castrén JA, Korhonen M. Significance of dacryocystography in lacrimal drainage system affections. Acta Ophthalmol (Kbh) 1964; 42: 188-92.

23 Malik SRK, Gupta AK, Chaterjee S, Bhardwaj OP, Saha M. 
Dacryocystography of normal and pathological lacrimal passages. Br J Ophthalmol 1969; 53: 174-9.

24 Saparoff GR, Chaudhuri T, Chaudhuri T, Dolan KD, Christie JH. Nuclear lacrimal scan vs dacryocystography. Trans Am Acad Ophthalmol Otolaryngol 1976; 81: OP 566-74.

25 Jacobs HB. Symptomatic epiphora. Br J Ophthalmol 1959; 43: 415-34.

26 Jones LT. The cure of epiphora due to canalicular disorders, trauma and surgical failures on the lacrimal passages. Trans Am Acad Ophthalmol Otolaryngol 1962; 66: 506-24.

27 Keast-Butler J, Lloyd GAS, Welham RAN. Analysis of intubation macrodacryocystography with surgical correlations. Trans Ophthalmol Soc UK 1973; 93: 593-6.

28 Welham RAN, Henderson PH. Results of dacryocysto- rhinostomy: analysis of causes of failure. Trans Ophthalmol Soc UK 1973; 93: 601-9.

29 Carlton WH, Trueblood JH, Rossomondo RM. Clinical evaluation of microscintigraphy of the lacrimal drainage apparatus. J Nucl Med Allied Sci 1973; 14: 89-92.

30 Campbell W. The radiology of the lacrimal system. Br J Radiol 1964; 37: 1-26.

31 Nahata MC. Dacryocystography: in diseases of the lacrimal sac. Am J Ophthalmol 1964; 58: 490-3.

32 Hurwitz JJ, Cooper PR, McRae DL, Chenoweth DR. The investigation of epiphora. Can J Ophthalmol 1977; 12: 196-8.

33 Robertson JS, Brown ML, Colvard DM. Radiation absorbed dose to the lens in dacryoscinitigraphy with ${ }^{99} \mathrm{TcO}_{4}$. Radiology 1979; 133: 747-50. 